\title{
Runs of homozygosity and inbreeding in thyroid cancer
}

\author{
Hauke Thomsen ${ }^{1 *}$, Bowang Chen ${ }^{1}$, Gisella Figlioli ${ }^{1,2}$, Rossella Elisei ${ }^{3}$, Cristina Romei ${ }^{3}$, Monica Cipollini ${ }^{2}$, \\ Alfonso Cristaudo ${ }^{3}$, Franco Bambi ${ }^{4}$, Per Hoffmann ${ }^{5,6,7}$, Stefan Herms ${ }^{5,6,7}$, Stefano Landi ${ }^{2}$, Kari Hemminki ${ }^{1,8}$, \\ Federica Gemignani ${ }^{2}$ and Asta Försti ${ }^{1,8}$
}

\begin{abstract}
Background: Genome-wide association studies (GWASs) have identified several single-nucleotide polymorphisms (SNPs) influencing the risk of thyroid cancer (TC). Most cancer predisposition genes identified through GWASs function in a co-dominant manner, and studies have not found evidence for recessively functioning disease loci in TC. Our study examines whether homozygosity is associated with an increased risk of TC and searches for novel recessively acting disease loci.
\end{abstract}

Methods: Data from a previously conducted GWAS were used for the estimation of the proportion of phenotypic variance explained by all common SNPs, the detection of runs of homozygosity $(\mathrm{ROH})$ and the determination of inbreeding to unravel their influence on TC.

Results: Inbreeding coefficients were significantly higher among cases than controls. Association on a SNP-by-SNP basis was controlled by using the false discovery rate at a level of $q^{*}<0.05$, with 34 SNPs representing true differences in homozygosity between cases and controls. The average size, the number and total length of $\mathrm{ROH}$ per person were significantly higher in cases than in controls. A total of 16 recurrent ROHs of rather short length were identified although their association with TC risk was not significant at a genome-wide level. Several recurrent $\mathrm{ROH}$ s harbor genes associated with risk of TC. All of the ROHs showed significant evidence for natural selection (iHS, $F_{s t}$, Fay and Wu's H).

Conclusions: Our results support the existence of recessive alleles in TC susceptibility. Although regions of homozygosity were rather small, it might be possible that variants within these ROHs affect TC risk and may function in a recessive manner.

Keywords: Thyroid cancer, Runs of homozygosity, Inbreeding, GWAS

\section{Background}

Thyroid cancer (TC) is the most common malignancy of the endocrine system with incidence rates being 2 to 3 times higher in women compared with men $[1,2]$. In economically developed countries, 0.5 to $10 \mathrm{TC}$ cases are diagnosed per 100000 individuals each year [1]. Significant regional differences are seen in Europe with Italy being among the countries with the highest incidence rates in the world (Cancer Incidence in Five Continents, IX, 2000, http://www.iarc.fr/en/publications/

\footnotetext{
* Correspondence: h.thomsen@dkfz-heidelberg.de

'Molecular Genetic Epidemiology, C050, German Cancer Research Center

(DKFZ), Im Neuenheimer Feld 580, 69120 Heidelberg, Germany

Full list of author information is available at the end of the article
}

pdfs-online/epi/sp160/). While exposure to ionizing radiation or insufficient iodine intake is an established risk factor, anthropometric risk factors such as high body surface area, great height, or excess weight have been associated with increased TC risk [3]. However, TC is also characterized by having one of the highest familial risks of any cancer supporting heritable predisposition [4-6]. A high risk of TC is associated with some genetic disorders, but most of the familial risk of TC remains unexplained [7]. During the last years genome-wide association studies (GWASs) have provided robust evidence for common susceptibility to TC. At least four GWASs have identified a set of genes with susceptibility for TC [8-11]. These studies suggest that much of the familial risk of TC may be due to the 
coinheritance of multiple low/moderate-penetrant alleles, some of which may be common. The majority of cancer predisposition genes identified through the GWASs function in a co-dominant manner, and no evidence has been found for recessively functioning disease loci in $\mathrm{TC}$, although the risk for $\mathrm{TC}$ among siblings is much higher than the parent-offspring risk, suggesting recessive inheritance [6]. Recessive inheritance has been associated with consanguinity or an increased risk in populations characterized by a higher degree of inbreeding and corresponding homozygosity [12]. A consecutive pattern, called runs of homozygosity $(\mathrm{ROH})$, appears mainly in an increased frequency due to a high level of relatedness between individuals within a population or due to selection [13]. These ROHs are shown to predispose to many genetic diseases including cancers [14-16]. The siblings-risk and the fact and that TC is part of recessively inherited syndromes such as the Werner syndrome make TC an ideal target to search for recessively acting disease loci [6, 7].

In a first step we estimated the proportion of the total phenotypic variance explained by all common SNPs for TC risk. This was followed by a whole-genome homozygosity analysis based on our previous GWAS in the high-incidence Italian population. The aim of our study was to examine whether inbreeding or homozygosity is associated with an increased risk of TC and to search for novel recessively acting disease loci.

\section{Methods}

\section{Ethics statement}

Study participants were recruited according to the protocols approved by the institutional review boards in accordance with the Declaration of Helsinki. All subjects provided written informed consent. This study was approved by the ethics committees of the University Hospitals of Cisanello and Santa Chiara in Pisa, Italy and of the Meyer Hospital in Florence, Italy.

\section{Genomic data - quality control of SNP genotyping}

The study is based on the genotyping data of our previously performed GWAS on the Italian cases and controls, and did not include any new participants [11, 17]. All patients were ascertained with papillary thyroid cancer (PTC) through the University Hospital Cisanello in Pisa. After a stringent quality control procedure the final set consisted of 649 cases and 431 controls with genotype data on 536270 SNPs [18, 19]. Data have been submitted to a central database: www.gwascentral.org.

\section{Proportion of the total phenotypic variance explained by} all common SNPs

The approach of Yang et al. was used to estimate the proportion of the total phenotypic variance explained by all common SNPs [20]. First, we estimated the genetic relationship matrix (GRM) for each individual autosome of all the individuals and fitted the GRMs in a mixed linear model (MLM) to estimate the proportion of the phenotypic variance explained by all common SNPs. We repeated this scenario after excluding 15 identified GWAS regions for TC including the genomic region $500 \mathrm{~kb}$ upstream and downstream [11, 17]. This left us with a total of 520137 autosomal SNPs.

For both scenarios sex and eigenvectors from 10 principal components of the population structure were used as covariates. Consecutive estimates on the observed 0-1 scale are linearly transformed to that on the unobserved continuous liability scale such that $\mathrm{h}_{\mathrm{l}}^{2}=\mathrm{h}_{0}^{2} \mathrm{~K}(1-\mathrm{K}) / \mathrm{z}^{2}$ [21], where $\mathrm{K}$ is the prevalence of the disease and $\mathrm{z}$ is the value of the standard normal probability density function at the threshold t. Given an incidence of $8-9 / 100000 /$ year will result in a cumulative risk of $\sim 6$ in 1000 as an estimate of the prevalence. Estimation was performed using restricted maximum likelihood (REML) via the genome-wide complex trait analysis (GCTA) software [22].

\section{Genome-wide assessment of associations between homozygosity at individual SNPs and TC}

A $\mathrm{chi}^{2}$-test was performed to test for any association between homozygosity and susceptibility of TC on a SNP-by-SNP basis in our entire sample series [14]. To control the problem of multiple testing the false discovery rate (FDR) was calculated and controlled at an arbitrary level $q^{*}<0.05[23]$.

\section{Statistical and bioinformatics analysis}

We defined ROHs following recommendations in Howrigan et al. [24] ROHs were detected using PLINK (v1.07) software. To prevent overestimating the number and size of ROHs no heterozygous SNPs were permitted in any window. We kept the remaining options to default values. The parameter for the "homozyg-kb" option was also kept at the default value of $1000 \mathrm{~kb}$ to select individual segments of minimal length. We only varied the parameter "homozyg-snp" option according to the definition of ROHs as below. Subsequent statistical analyses were performed using packages available in the $\mathrm{R}$ statistics package [25]. Comparison of the distribution of categorical variables was performed using the $\mathrm{chi}^{2}$-test. To compare the difference in the average number of ROHs between cases and controls, we used the Student's $t$-test. Naive adjustment for multiple testing was based on the Bonferroni correction.

\section{Identification of homozygosity}

We used the method of Lencz et al. to estimate the minimum number of consecutive homozygous SNPs 
required to form a $\mathrm{ROH}$ that was more than an order of magnitude larger than the mean haploblock size in the human genome without being too large to be very rare [26]. In our TC data, with 1080 individuals and 536270 SNPs, the mean heterozygosity in controls was calculated to be $35 \%$. Thus, a minimum length of 53 would be required to produce $<5 \%$ randomly generated $\mathrm{ROHs}$ across all subjects: $\left((1-0.35)^{53} \times 536270 \times 1080 \leq 0.05\right)$. Due to linkage disequilibrium (LD) between the SNPs, the SNP genotypes are not always independent. Pairwise LD was estimated using the SNP pruning function of PLINK, with a default value of $r^{2}>0.8$ and restricting the search of tagging SNPs within each $250 \mathrm{~kb}$ window. Approximately 377000 separable tag groups were

Table 1 Association between homozygosity and susceptibility to TC for individual SNPs

\begin{tabular}{|c|c|c|c|c|c|c|c|c|c|c|}
\hline SNP & $\mathrm{CHR}$ & $\mathrm{BP}^{\mathrm{a}}$ & Cases AA/BB & Cases $A B$ & Controls AA/BB & Controls $A B$ & $\mathrm{chi}^{2}$ & $p^{b}$ & $q^{* c}$ & Genes \\
\hline rs4698482 & 4 & 16020011 & 519 & 116 & 274 & 157 & 44.43 & $2.62 \times 10^{-11}$ & $1.40 \times 10^{-5}$ & LDB2 \\
\hline rs11688848 & 2 & 204624451 & 512 & 119 & 275 & 156 & 40.10 & $2.40 \times 10^{-10}$ & $5.38 \times 10^{-5}$ & ICOS \\
\hline rs9578483 & 13 & 22068754 & 543 & 97 & 296 & 135 & 39.66 & $3.01 \times 10^{-10}$ & $5.38 \times 10^{-5}$ & FGF9, FTHL7 \\
\hline rs839509 & 2 & 212530542 & 497 & 126 & 270 & 160 & 37.09 & $1.12 \times 10^{-9}$ & 0.0001 & $\begin{array}{l}\text { ERBB4, CPS1, } \\
\text { hCG_1645016 }\end{array}$ \\
\hline rs2414003 & 15 & 48105489 & 514 & 122 & 280 & 151 & 33.90 & $5.77 \times 10^{-9}$ & 0.0006 & ATP8B4, SLC27A2 \\
\hline rs3096381 & 16 & 69875502 & 525 & 116 & 289 & 141 & 30.46 & $3.39 \times 10^{-8}$ & 0.0028 & FU11171, HYDIN, CALB2 \\
\hline rs630695 & 6 & 117359452 & 526 & 103 & 299 & 132 & 30.10 & $4.09 \times 10^{-8}$ & 0.0028 & RFXDC1, GPRC6A, VGLL2 \\
\hline rs938845 & 18 & 63860975 & 512 & 122 & 284 & 147 & 30.02 & $4.26 \times 10^{-8}$ & 0.0028 & NA \\
\hline rs17797954 & 5 & 174303096 & 516 & 122 & 287 & 144 & 28.09 & $1.15 \times 10^{-7}$ & 0.0068 & DRD1 \\
\hline rs10961997 & 9 & 15361675 & 509 & 134 & 279 & 152 & 27.48 & $1.58 \times 10^{-7}$ & 0.0083 & SNAPC3 \\
\hline rs12126497 & 1 & 166939482 & 586 & 56 & 346 & 85 & 27.33 & $1.71 \times 10^{-7}$ & 0.0083 & DPT, XCL1 \\
\hline rs509716 & 6 & 131475408 & 532 & 113 & 297 & 134 & 26.90 & $2.13 \times 10^{-7}$ & 0.0095 & EPB41L2, AKAP7 \\
\hline rs6715968 & 2 & 229884476 & 484 & 141 & 272 & 159 & 25.75 & $3.86 \times 10^{-7}$ & 0.0159 & PID1, DNER \\
\hline rs712082 & 1 & 222792683 & 545 & 98 & 311 & 120 & 25.32 & $4.83 \times 10^{-7}$ & 0.0173 & WDR26, AKR1B1P1 \\
\hline rs6440553 & 3 & 149713261 & 545 & 84 & 321 & 110 & 25.32 & $4.84 \times 10^{-7}$ & 0.0173 & RPL38P1 \\
\hline rs8043171 & 15 & 90065471 & 529 & 105 & 304 & 127 & 25.07 & $5.50 \times 10^{-7}$ & 0.0184 & SLCO3A1 \\
\hline rs12902263 & 15 & 69429108 & 556 & 87 & 321 & 110 & 24.77 & $6.44 \times 10^{-7}$ & 0.0197 & $\begin{array}{l}\text { THSD4, hCG_2004593, } \\
\text { NR2E3 }\end{array}$ \\
\hline rs10254361 & 7 & 119351441 & 522 & 116 & 296 & 135 & 24.72 & $6.62 \times 10^{-7}$ & 0.0197 & KCND2 \\
\hline rs11563992 & 7 & 27347461 & 507 & 115 & 294 & 136 & 24.16 & $8.86 \times 10^{-7}$ & 0.0242 & NA \\
\hline rs7018634 & 9 & 20249528 & 538 & 100 & 310 & 121 & 24.11 & $9.05 \times 10^{-7}$ & 0.0242 & SLC24A2, SMNP \\
\hline rs11169076 & 12 & 48261675 & 571 & 72 & 335 & 96 & 23.99 & $9.68 \times 10^{-7}$ & 0.0247 & MCRS1, FAM186B \\
\hline rs1943939 & 18 & 69856260 & 556 & 62 & 342 & 89 & 23.22 & $1.43 \times 10^{-6}$ & 0.0332 & FBXO15, \\
\hline rs12660310 & 6 & 167051901 & 503 & 120 & 292 & 139 & 23.18 & $1.46 \times 10^{-6}$ & 0.0332 & RPS6KA2, RNASET2 \\
\hline rs11204947 & 1 & 150484881 & 489 & 135 & 280 & 151 & 23.16 & $1.48 \times 10^{-6}$ & 0.0332 & HRNR, FLG, \\
\hline rs3821310 & 2 & 74923771 & 581 & 61 & 345 & 85 & 23.06 & $1.56 \times 10^{-6}$ & 0.0335 & HK2, SEMA4F, POLE4 \\
\hline rs9407406 & 9 & 8229748 & 532 & 95 & 314 & 117 & 22.93 & $1.67 \times 10^{-6}$ & 0.0345 & C9orf123, PTPRD \\
\hline rs2830028 & 21 & 26349119 & 493 & 133 & 282 & 148 & 22.64 & $1.94 \times 10^{-6}$ & 0.0386 & APP, GABPA, CYYR1 \\
\hline rs11151652 & 18 & 67133203 & 554 & 91 & 319 & 110 & 22.52 & $2.07 \times 10^{-6}$ & 0.0397 & CBLN2 \\
\hline rs10779770 & 1 & 12529312 & 537 & 97 & 314 & 117 & 22.42 & $2.18 \times 10^{-6}$ & 0.0403 & VPS13D, DHRS3 \\
\hline rs1508833 & 5 & 38050010 & 519 & 108 & 303 & 127 & 22.35 & $2.26 \times 10^{-6}$ & 0.0404 & GDNF, EGFLAM \\
\hline rs554232 & 8 & 102533760 & 540 & 98 & 314 & 117 & 22.23 & $2.40 \times 10^{-6}$ & 0.0408 & NACAP1, GRHL2 \\
\hline rs2102727 & 8 & 53063166 & 502 & 133 & 285 & 146 & 22.21 & $2.43 \times 10^{-6}$ & 0.0408 & PCMTD1, ST18, \\
\hline rs9379246 & 6 & 8777273 & 571 & 67 & 341 & 90 & 22.11 & $2.56 \times 10^{-6}$ & 0.0416 & HULC \\
\hline rs7481683 & 11 & 8157762 & 454 & 174 & 252 & 179 & 21.98 & $2.75 \times 10^{-6}$ & 0.0434 & RIC3, LMO1 \\
\hline
\end{tabular}

${ }^{a}$ Genome build hg18

${ }^{b} P$ was calculated using a simple $2 \times 2 \mathrm{chi}^{2}$ test based on the number of homozygotes and heterozygotes at each SNP in cases and controls ${ }^{c} q$ values representing the false discovery rate (FDR) 
discovered, representing an $>25 \%$ reduction of information compared with the original number of SNPs. Thus, $\mathrm{ROH}$ length of 75 was used to approximate the degrees of freedom of 53 independent SNP calls.

The $\mathrm{R}$ statistics package was used to identify a list of 'common' ROHs with 75 consecutive homozygous SNP calls across a certain number of samples and with each $\mathrm{ROH}$ having identical start and end locations across the individuals. The "homozyg-group" option of the PLINK package was used to produce a file of the overlapping ROHs separated into pools containing the number of cases and controls carrying the $\mathrm{ROH}$. We considered pools with more than five samples and at least $500 \mathrm{~kb}$ of length as recurrent ROHs. A consensus SNP set representing the minimal overlapping region across all samples in the pool was used to define the recurrent ROHs. The association of the recurrent $\mathrm{ROHs}$ was then tested for differences of the average proportion of $\mathrm{ROHs}$ among cases and controls. Within each overlapping $\mathrm{ROH}$ the proportion of homozygous genotypes at each SNP was calculated for cases and controls separately, and the significance of the difference was tested by a onetailed $t$-test.

\section{Testing the effects of natural selection}

We used three metrics, the integrated haplotype score (iHS), the fixation index $\left(\mathrm{F}_{\mathrm{st}}\right)$ and Fay and Wu's $\mathrm{H}$ to investigate the selective pressure due to demographic events (e.g. bottleneck events, founder effects or population isolation) on each recurrent $\mathrm{ROH}[27,28]$. All metrics were obtained from Haplotter Software (University of Chicago, Chicago, IL, USA; http://haplotter.uchicago.edu/) [28, 29].

\section{Testing the effects of inbreeding}

To test whether inbreeding influenced the susceptibility to TC, three different inbreeding coefficients (F I, F II and F III) were derived for each individual based on their SNP data using GCTA [22]. The coefficients were tested for differences between cases and controls using a Student's $t$-test. We also used a generalized linear regression model (GLM) and regressed F I, F II or F III as explanatory variables on the disease status of the TC patient as the binary response $(0 / 1)$. We included several covariates in the model: the sex of the individuals, the first 10 ancestry-informative principal components and the percentage of SNPs missing for an individual.

A genomic measure of individual homozygosity $\left(\mathrm{F}_{\mathrm{ROH}}\right)$ was calculated by a method proposed by McQuillan et al. [30] in which $\mathrm{L}_{\mathrm{ROH}}$ is the sum of ROHs per individual above a certain criterion length (i.e. $1000 \mathrm{~kb}$ as defined beforehand) and $\mathrm{L}_{\mathrm{AUTO}}$ is the total
SNP-mappable autosomal genome length, excluding the centromeres:

$$
\mathrm{F}_{\mathrm{ROH}}=\sum \mathrm{L}_{\mathrm{ROH}} / \mathrm{L}_{\mathrm{AUTO}}
$$

The estimate of the total genome captured was 2677608 $286 \mathrm{bp} . \mathrm{F}_{\mathrm{ROH}}$ estimates inbreeding differently compared to the coefficients based on SNP-by-SNP indices F I, F II and F III as it considers only homozygous regions above a predefined length criterion (i.e. $1000 \mathrm{~kb}$ ). Due to the $\mathrm{F}_{\mathrm{ROH}}$ distribution in our sample we divided ROHs into two classes, below and above $1500 \mathrm{~kb}$, and $\mathrm{F}_{\mathrm{ROH}}$ was calculated overall, and for the two subclasses using the $\mathrm{R}$ statistics package [25]. The overall $F_{\mathrm{ROH}}$ was also tested for differences between cases and controls using a Student's $t$-test.

\section{Results}

After stringent quality control and exclusion of extreme population outliers the overall genetic matching was satisfying with a genomic control inflation factor at $\lambda_{\mathrm{gc}}=1.00$ within the prior GWAS, indicating that no population stratification was present [11].

Proportion of total phenotypic variance explained by SNPs The proportion of the total phenotypic variance explained by SNPs from the joint analysis transformed to the liability scale after Dempster and Lerner showed a value of 0.51 (SE 0.16 at $P \leq 1.97 \times 10^{-7}$ ) [21]. After the exclusion of the regions covered by the previously identified TC risk SNPs the proportion of the total phenotypic variance explained by the so far unidentified SNPs was 0.33 (SE 0.15 at $P \leq 0.003$ ). While most of variance explained by common SNPs for individual autosomes stayed constant, a major drop was detected for chromosome 2 encompassing

Table 2 Association between overall $\mathrm{ROH}$ and TC (min. 75 SNPs per $\mathrm{ROH}$ )

\begin{tabular}{|c|c|c|c|c|c|}
\hline \multirow[b]{2}{*}{ Number of $\mathrm{ROH}^{\mathrm{a}}$} & \multicolumn{3}{|c|}{ Entire data set } & \multirow[b]{2}{*}{$95 \% \mathrm{Cl}$} & \multirow[b]{2}{*}{$P$} \\
\hline & Cases & Controls & OR & & \\
\hline$<10$ & 204 & 152 & 1.00 & Ref. & \\
\hline $10-12$ & 145 & 88 & 1.22 & $0.87-1.72$ & 0.23 \\
\hline $13-15$ & 170 & 127 & 0.99 & $0.73-1.36$ & 0.98 \\
\hline$>15$ & 130 & 64 & 1.55 & $1.05-2.18$ & 0.02 \\
\hline \multicolumn{6}{|l|}{ Total length (Mb) } \\
\hline$<14.1$ & 153 & 117 & 1.00 & Ref. & \\
\hline $14.1-19.4$ & 156 & 114 & 1.04 & $0.74-1.47$ & 0.79 \\
\hline $19.4-25.4$ & 163 & 107 & 1.16 & $0.82-1.64$ & 0.38 \\
\hline$>25.4$ & 177 & 93 & 1.45 & $1.02-2.06$ & 0.03 \\
\hline
\end{tabular}

${ }^{a}$ Cutoffs were chosen to produce approximately equal group sizes for cases and controls 
DIRC3 (from 0.11 to 0.03 ) and for chromosome 9 encompassing FOXE1 (from 0.17 to 0.08).

\section{Genome-wide assessment of associations between} homozygosity at individual SNPs and susceptibility to TC Results of the association between homozygosity and the susceptibility to TC on a SNP-by-SNP basis are shown in Table 1. The FDR was calculated and controlled at an arbitrary level $\mathrm{q}^{*}<0.05$, for which 34 SNP were significant [23]. Corresponding odds ratios (ORs) of the onesided Fisher's exact test to prove the hypothesis that increased homozygosity is associated with higher risk of TC showed a minimum of OR $=1.85$ with a $95 \%$ confidence interval of 1.23-3.41 for all SNPs in Table 1.

Table 3 List of ROHs associated with TC

\begin{tabular}{|c|c|c|c|c|c|c|c|c|c|c|}
\hline $\mathrm{ROH}$ & Chr. & Start - End (bp) ${ }^{a}$ & Cases/controls & $\mathrm{Chi}^{2}$ & $p^{b}$ & $P^{c}$ & iHS max ${ }^{d}$ & $\mathrm{~F}_{\mathrm{st} \max }^{\mathrm{e}}$ & Fay and Wu's $H^{f}$ & Genes $^{g}$ \\
\hline $\mathrm{ROH} 1$ & 2 & $167204846-167895993$ & $6 / 15$ & 8,87 & 0.002 & $1.44 \times 10^{-4}$ & 3.50 & 0.50 & -74.64 & XIRP2 \\
\hline $\mathrm{ROH} 2$ & 3 & $121016843-121689105$ & $10 / 0$ & 6,70 & 0.009 & $9.43 \times 10^{-6}$ & 2.76 & 0.50 & -37.03 & $\begin{array}{l}\text { GSK3B, FSTL1, LRRC58, } \\
\text { GPR156 }\end{array}$ \\
\hline $\mathrm{ROH} 3$ & 10 & $44969326-45928700$ & $5 / 11$ & 5,63 & 0.01 & $6.12 \times 10^{-5}$ & 1.85 & 0.35 & -57.08 & $\begin{array}{l}\text { ALOX5, OR13A1, ANUBL1, } \\
\text { CTGLF1, MARCH8, OR6D1P, } \\
\text { FAM21C, CTGLF10P }\end{array}$ \\
\hline $\mathrm{ROH} 4$ & 6 & $69734043-70381283$ & $2 / 7$ & 5,42 & 0.01 & 0.007 & 2.58 & 0.27 & -31.48 & $\mathrm{BAI} 3^{\mathrm{g}}$ \\
\hline $\mathrm{ROH} 5$ & 9 & $73966521-74829925$ & $2 / 7$ & 5,42 & 0.01 & $1.60 \times 10^{-12}$ & 2.05 & 0.44 & -19.76 & ALDH1A1, ZFAND5, TMC1 \\
\hline $\mathrm{ROH} 6$ & 1 & $217208583-218034929$ & $7 / 0$ & 4,67 & 0.03 & 0.08 & 2.17 & 0.41 & -55.42 & LYPLAL1, ZC3H11B \\
\hline $\mathrm{ROH7}$ & 2 & $26036646-26765583$ & $7 / 0$ & 4,67 & 0.03 & 0.18 & 2.42 & 0.61 & -64.28 & $\begin{array}{l}\text { HADHA, HADHB, OTOF, } \\
\text { RAB10, SELI, C2orf39, } \\
\text { CIB4, FAM59B, PPIL1P1, } \\
\text { GPR113, C2orf70 }\end{array}$ \\
\hline $\mathrm{ROH} 8$ & 2 & $75174688-76481471$ & $7 / 0$ & 4,67 & 0.03 & 0.03 & 2.78 & 0.57 & -66.54 & C2orf3, MRPL19, FAM176A, \\
\hline $\mathrm{ROH} 9$ & 1 & $177243354-178385972$ & $6 / 0$ & 4,00 & 0.04 & $1.67 \times 10^{-4}$ & 2.67 & 0.38 & -56.96 & $\begin{array}{l}\text { ABL2, SOAT1, NPHS2, } \\
\text { CEP350, FAM20B, } \\
\text { TOR1AIP1, IFRG15, } \\
\text { TOR3A, C1 orf125, } \\
\text { FAM163A, TDRD5, } \\
\text { TOR1AIP2 }\end{array}$ \\
\hline $\mathrm{ROH} 10$ & 2 & $112182736-113192306$ & $6 / 0$ & 4,00 & 0.04 & 0.02 & 2.54 & 0.41 & -24.47 & $\begin{array}{l}\text { SLC20A1, MERTK, ANAPC1, } \\
\text { POLR1B, CHCHD5, ZC3H8, } \\
\text { TMEM87B, FBLN7, TTL, } \\
\text { ZC3H6, RGPD8, }\end{array}$ \\
\hline $\mathrm{ROH} 11$ & 2 & $113858688-114678121$ & $6 / 0$ & 4,00 & 0.04 & 0.83 & 2.37 & 0.50 & -48.23 & $\begin{array}{l}\text { ACTR3, RABL2A, SLC35F5, } \\
\text { RPL23AP7, CBWD2, } \\
\text { RP11-395 L14.12, } \\
\text { FOXD4L1, WASH2P }\end{array}$ \\
\hline $\mathrm{ROH} 12$ & 4 & $181001922-181547116$ & $6 / 0$ & 4,00 & 0.04 & 0.33 & 2.29 & 0.53 & -36.74 & NA \\
\hline $\mathrm{ROH} 13$ & 4 & $182307562-182564832$ & $6 / 0$ & 4,00 & 0.04 & 0.35 & 2.09 & 0.30 & -31.12 & hCG_2025798 \\
\hline $\mathrm{ROH} 14$ & 4 & $183848547-184539543$ & $6 / 0$ & 4,00 & 0.04 & $1.00 \times 10^{-8}$ & 2.09 & 0.65 & -56.96 & $\begin{array}{l}\text { DCTD, CLDN22, WWC2, } \\
\text { C40rf38, FAM92A3, } \\
\text { CLDN24 }\end{array}$ \\
\hline $\mathrm{ROH} 15$ & 9 & $107008151-108187183$ & $6 / 0$ & 4,00 & 0.04 & 0.51 & 2.75 & 0.58 & -46.35 & $\begin{array}{l}\text { FKTN, TAL2, SLC44A1, } \\
\text { GARNL2P, TMEM38B, } \\
\text { FSD1L, DEPDC1P2 }\end{array}$ \\
\hline $\mathrm{ROH} 16$ & 15 & $96502627-98965249$ & $6 / 0$ & 4,00 & 0.04 & $3.01 \times 10^{-12}$ & 3.09 & 0.65 & -110.70 & $\begin{array}{l}\text { IGF1R, MEF2A, HSP90B2P, } \\
\text { SYNM, LINS1, TTC23, } \\
\text { LRRC28, LYSMD4, } \\
\text { ADAMTS17, C15orf51, } \\
\text { LASS3, FAM169B, } \\
\text { FLJ42289, PRKXP1 }\end{array}$ \\
\hline
\end{tabular}

\footnotetext{
${ }^{a}$ Chromosomal positions derived from the National Center for Biotechnology Information (NCBI), build 36, hg18 ${ }^{\mathrm{b}}$ Suggestive significance

'Significances for testing differences in homozygosity with $\mathrm{H}_{0}: \mu_{\text {Cases }}=\mu_{\text {Controlsi }} \mathrm{H}_{1}: \mu_{\text {Cases }}>\mu_{\text {Controlsi }}$.

${ }^{\mathrm{d}}$ Represents maximal absolute values for iHS, derived for CEU population ancestry from Haplotter, Phase II (http://haplotter.uchicago.edu/)

${ }^{e}$ Represents maximal values for $F_{\text {st }}$, derived for CEU population ancestry from Haplotter, Phase II

Represents minimum values for Fay and Wu's $\mathrm{H}$, derived for CEU population ancestry from Haplotter, Phase II

in flanking region
} 
Identification of ROHs and association between ROHs and TC susceptibility

We identified a total of 12306 individual ROHs greater than $1000 \mathrm{~kb}$ across all 1080 individuals with 7523 ROHs in cases and 4783 ROHs in controls. On average $11.39 \mathrm{ROH}$ segments with a total overall length of 22 $980 \mathrm{~kb}$ per individual were detected. The average number of $\mathrm{ROH}$ segments per person in cases was 11.59 and in controls $11.09\left(P_{\text {diff }}=4.00 \times 10^{-2}\right)$, the total length of ROHs per person was $4761 \mathrm{~kb}$ higher in cases than in controls $\left(P_{\text {diff }}=1.95 \times 10^{-5}\right)$, and the average $\mathrm{ROH}$ length per person in $\mathrm{kb}$ was significantly higher in cases $(1988 \mathrm{~kb})$ than in controls $(1788 \mathrm{~kb})\left(P_{\text {diff }}=3.29 \times 10^{-8}\right)$.

We extended the tests for association between $\mathrm{ROHs}$ and susceptibility to $\mathrm{TC}$ by categorizing the number of $\mathrm{ROHs}$ and the total length of ROHs in $\mathrm{Mb}$ by forming control groups of similar size. They were compared with the numbers of cases within the corresponding classes (Table 2). Cases had more ROHs and the total length of ROHs was also longer than in controls. (e.g. for entire data set $>15 \mathrm{ROHs}, \mathrm{OR}=1.55, P=0.02$; for $>25.4 \mathrm{Mb}$, $\mathrm{OR}=1.45, P=0.03)$.

For further association analysis 2262 consensus groups were formed, of which a total of 225 ROHs were identified, that fulfilled the criteria of identical start and end location and at least 75 consecutive homozygous SNPs [26]. An example for an overlapping region is given in the Additional file 1: Figure S1. None of the ROHs were associated with susceptibility to TC after correction for multiple testing. However, 16 ROHs were associated at a suggestive level $(P<=0.05)$ (Table 3). None of them encompassed the centromeric regions.

Intriguingly, several recurrent $\mathrm{ROHs}$ harbor genes that have been associated with risk or progression of TC (Table 3). The first consensus region, located on chromosome 2, shows the strongest association with TC susceptibility (uncorrected P value $=0.002$, ROH1 in Table 3). Six cases and 15 controls carried a $\mathrm{ROH}$ spanning this region of 79 homozygous SNPs. Another consensus region on chromosome 3 (ROH2) spans $672 \mathrm{~kb}$ and contains 98 SNPs. Genes and predicted transcripts include GSK3B, FSTL1, LRRC58, GPR156. A consensus region on chromosome 10 spanning 81 SNPs on a length of $959 \mathrm{~kb}$ (ROH3, $P=0.01$ ) also hosts a considerable number of genes.

To scrutinize the significant $\mathrm{ROH}$ consensus regions, the average homozygosity for all SNP loci within a corresponding $\mathrm{ROH}$ was computed for cases and controls separately and tested for a difference with a one-tailed Student's $t$-test (Table 3, column 9). Ten ROHs showed significant differences at $P<0.05$ level, of which 6 had more cases than controls.

\section{Natural selection as a cause of ROHs}

To assess the influence of selection on the recurrent $\mathrm{ROH}$ regions, we used the measures $\mathrm{iHS}, \mathrm{F}_{\mathrm{st}}$ and Fay and Wu's $\mathrm{H}[28,29,31,32]$. Every recurrent $\mathrm{ROH}$ showed significant values for the three estimates (iHS $>2.0$, Fst $>0.2$ and Fay and Wu's $\mathrm{H}<<-10$; Table 3), except for ROH3, for which the iHS value was 1.85 . This indicates that each of the $16 \mathrm{ROH}$ regions might be the result of a selective sweep.

\section{Inbreeding and association between homozygosity and TC}

We formally calculated the inbreeding coefficients (so called F I, F II and F III) after Yang et al. for all samples [22]. The means (SDs) for F I in cases and controls were $0.003(0.01)$ and -0.0005 (0.006), respectively, and significantly different from each other $\left(P=2.94 \times 10^{-13}\right.$, by Student's $t$-test $)$. Thus, there was significant evidence that cases were more inbred than controls. This was supported by the inbreeding coefficient F III, which also differed significantly between cases and controls at $P=3.77 \times 10^{-6}$ with

\begin{tabular}{|c|c|c|c|c|}
\hline CHR. & Length in BP & $\left.\mathrm{F}\right|^{*}$ & $\mathrm{~F} \|^{*}$ & $\mathrm{~F}\|\|^{*}$ \\
\hline 1 & 239482994 & 0.16 & 0.39 & 0.22 \\
\hline 2 & 237975642 & 0.006 & 0.01 & 0.01 \\
\hline 3 & 195481660 & 0.19 & 0.28 & 0.11 \\
\hline 4 & 187415093 & 0.0002 & 0.01 & 0.008 \\
\hline 5 & 175834594 & $4.52 \times 10^{-5}$ & 0.03 & 0.0009 \\
\hline 6 & 165666786 & 0.09 & 0.50 & 0.64 \\
\hline 7 & 154972229 & 0.01 & 0.72 & 0.36 \\
\hline 8 & 141209234 & 0.0004 & 0.69 & 0.04 \\
\hline 9 & 126549725 & 0.12 & 0.22 & 0.17 \\
\hline 10 & 131868223 & 0.02 & 0.54 & 0.11 \\
\hline 11 & 129246417 & 0.27 & 0.60 & 0.71 \\
\hline 12 & 128925838 & 0.01 & 0.30 & 0.07 \\
\hline 13 & 91046560 & 0.01 & 0.15 & 0.15 \\
\hline 14 & 82460885 & 0.44 & 0.80 & 0.82 \\
\hline 15 & 77621221 & 0.07 & 0.74 & 0.12 \\
\hline 16 & 82341226 & 0.26 & 0.66 & 0.68 \\
\hline 17 & 77544622 & 0.02 & 0.55 & 0.41 \\
\hline 18 & 74113617 & 0.23 & 0.57 & 0.78 \\
\hline 19 & 60064206 & 0.02 & 0.13 & 0.04 \\
\hline 20 & 59665714 & 0.002 & 0.47 & 0.09 \\
\hline 21 & 30132781 & 0.001 & 0.89 & 0.15 \\
\hline 22 & 27989019 & 0.63 & 0.63 & 0.67 \\
\hline
\end{tabular}

*bold values show significant differences between cases and controls at $P<0.05$ 
cases being more inbred. The inbreeding coefficient F II was in cases $0.002(0.01)$ and in controls 0.001 (0.007), but differences were not significant. Table 4 lists the P values for the test of true differences of F I, F II and F III between cases and controls separately for each chromosome. Chromosomes 2, 4, 5 and 8 were significantly different. For all chromosomes cases showed higher values for F I, F II and F III than controls.

When using a GLM with several covariates and regressing the explanatory variables F I, F II or F III on the disease status of the TC patient as the binary response (0/1), F I and F III remained significant at $P=0.003$ with a positive effect estimate of 32.19 and 64.38 , respectively. This results in an increasing slope of the regression line towards the diseased individuals. F II was also significant at $P=0.01$.

A more detailed overview on the characteristics of the inbreeding coefficient for cases and controls is demonstrated in Fig. 1, which shows the variation of the inbreeding coefficient between chromosomes. The mean is rather constant across the chromosomes but the variation is increasing from chromosome 1 to 22 while the length of the chromosomes in base pairs is decreasing $\left(r=-0.80, P=6.51 \times 10^{-6}\right)$.

Three additional associations for different consanguinity measures were tested (Fig. 2). The total length of individual $\mathrm{ROHs}$ was highly correlated with the total number of ROHs per individual $(r=0.77$,
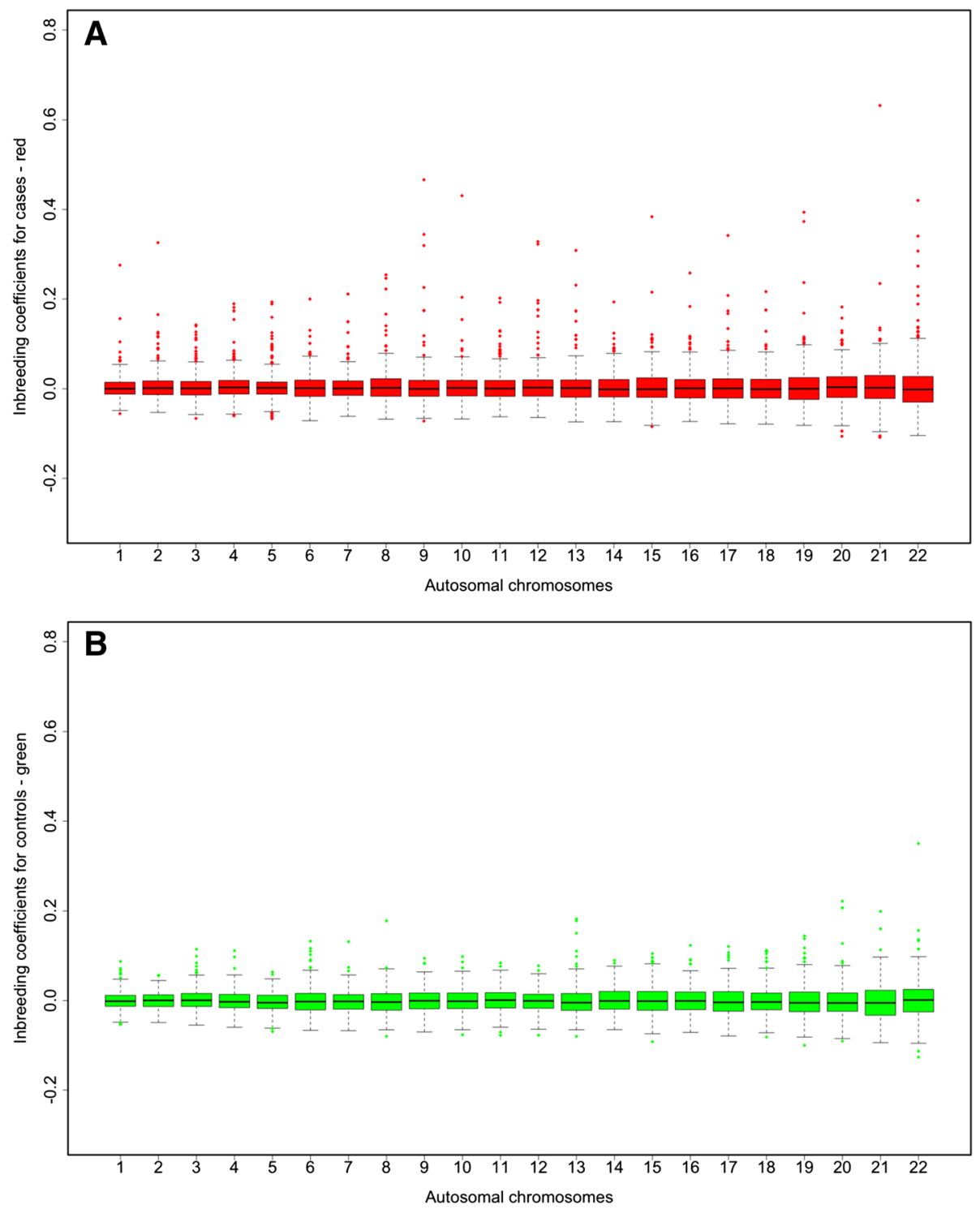

Fig. 1 Variation of inbreeding coefficients among chromosomes for cases (a) and controls (b). The boxplot figure shows the means and variation of the inbreeding coefficient F I for autosomal chromosomes 1 to 22 for cases (red) and controls (green) 

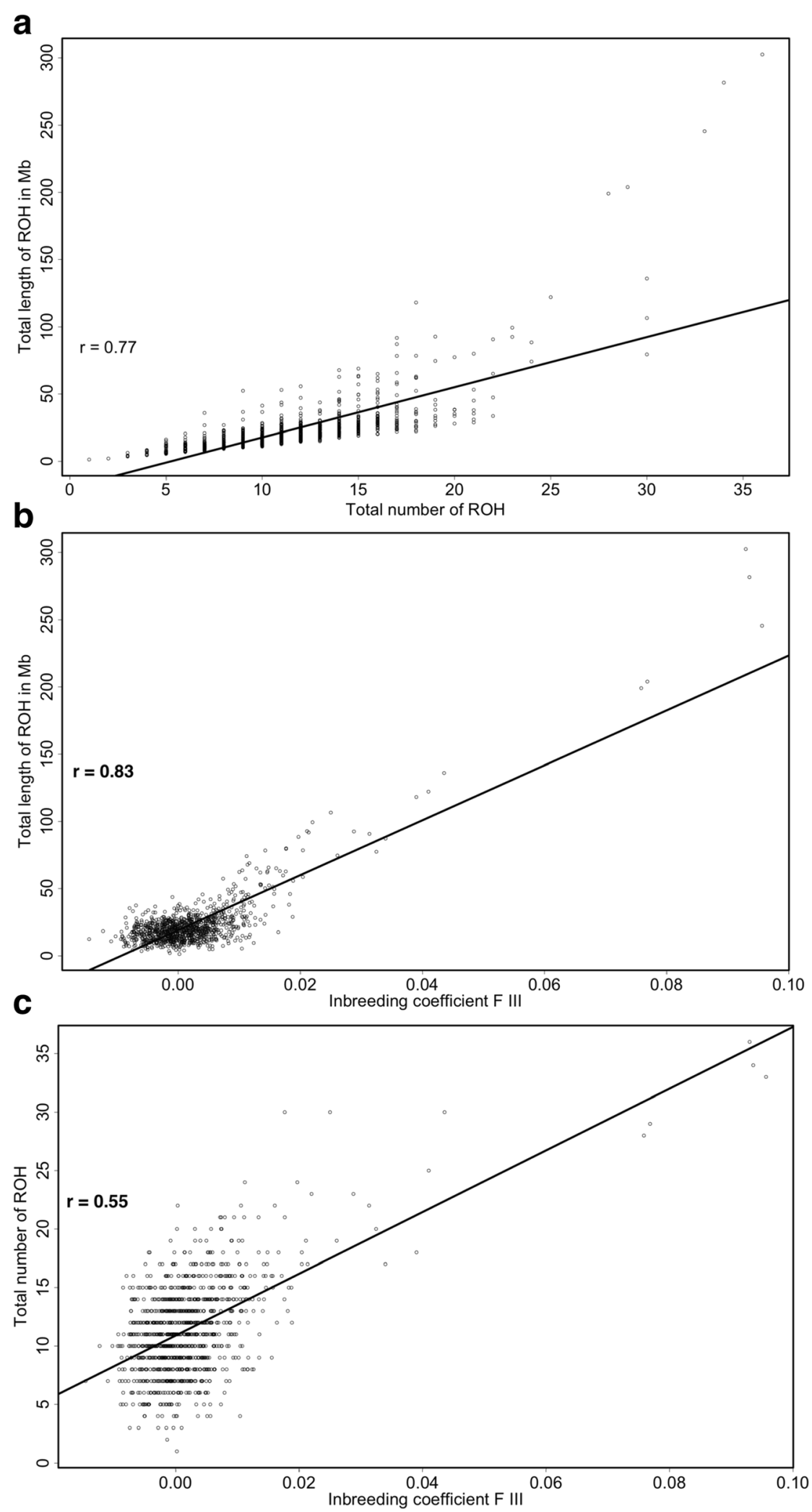

Fig. 2 (See legend on next page.) 
(See figure on previous page.)

Fig. 2 Pearson's correlation coefficients for different consanguinity measures. The total length of individual ROHs is highly correlated with the total number of $\mathrm{ROH}$ s per individual $\left(r=0.77, P<2.20^{*} 10^{-16}\right)(\mathbf{a})$. A high association is determined for the total length of $\mathrm{ROH}$ in $\mathrm{Mb}$ and the individual inbreeding coefficient F III $\left(r=0.83, P<2.20^{*} 10^{-16}\right)(\mathbf{b})$, while the lowest association was determined for the total number of ROHs per individual and the individual inbreeding coefficient $F$ III $\left(r=0.55, P<2.20^{*} 10^{-16}\right)(\mathbf{c})$

$\left.P<2.20 \times 10^{-16}\right)$. A significant association was also determined for the total length of ROHs per individual and the individual inbreeding coefficient F III $(r=0.83$, $P<2.20 \times 10^{-16}$ ) and for the total number of $\mathrm{ROHs}$ per individual and the individual inbreeding coefficient F III $\left(r=0.55, P<2.20 \times 10^{-16}\right)$.

Finally, $\mathrm{F}_{\mathrm{ROH}}$ was also 0.22 units of standard deviation SD $\left(P=1.95 \times 10^{-5}\right)$ higher in cases than controls. The correlation between the inbreeding coefficients and $\mathrm{F}_{\mathrm{ROH}}$ were also highly significant (F I: $r=0.71, P=2.20 \times 10^{-16}$; F II: $r=0.72, P=2.20 \times 10^{-16}$; F III: $r=0.83, P=2.20 \times 10^{-16}$ ).

\section{Discussion}

Based on our previous GWAS we showed here that the proportion of the total phenotypic variance in $\mathrm{TC}$ risk explained by all common SNPs is about 0.51. After correcting for identified TC risk loci about two-thirds of the genetic variance remain to be identified [11, 17]. This fact clearly shows the high influence of both the genetic factors and the environment on the susceptibility of TC. In the present study, we sought to find other genetic explanations than genes identified through previous GWASs that function in a co-dominant manner. The focus was shifted towards recessive inheritance. The current work is to our knowledge the first analysis of the influence of genomic homozygosity and genomic inbreeding on the susceptibility to TC.

Already the genome-wide SNP-by-SNP analysis showed significantly higher proportion of homozygous genotypes among the cases than controls. Further downstream analyses revealed significant differences between cases and controls in terms of the number and length of ROHs per person.

It is known that homozygosity can be caused by demographic events, consanguinity/inbreeding or selective pressure [33, 34]. Most of the ROHs in our study were rather short though. This excludes recent consanguinity as the cause of inbreeding. However, the significant genomic inbreeding coefficients point to a certain level of relatedness that might remain from distant consanguinity. All the ROHs of interest showed significant evidence for natural selection (iHS, $F_{\text {st }}$, Fay and Wu's H) [28]. The influence of selective pressure on the $\mathrm{ROH}$ length can therefore not be excluded.

The analysis of specific overlapping $\mathrm{ROHs}$ did not result in a genome-wide significance, however, several ROHs were matching with regions that contain genes related to TC susceptibility. The majority of overlapping ROHs was absent in controls. Homozygosity in these ROHs might have been disappeared over time due to recombination. Only for ROH1, ROH3, ROH4 and ROH5 we detected more controls than cases to be homozygous for an overlapping $\mathrm{ROH}$ region. One of these, $\mathrm{ROH} 5$ overlaps with long contiguous stretches of homozygosity from other studies $[35,36]$. However, in 10 out of 16 consensus regions significantly higher amount of homozygous SNPs were observed among cases than among controls. Thus, the inheritance of recessive genes harbored in these regions might be possible.

Our study shows some evidence of an association between extended stretches of homozygosity and an increased TC risk. This result is not unexpected as several studies before have detected association between ROHs and cancer susceptibility [16].

The novel result of our study is the significant effect of genomic inbreeding among cases and its relevant effect on the development of the disease. The inbreeding coefficients F I, F II, and F III were significantly higher in cases than in controls, even after correcting for numerous covariates using GLM. Inbreeding is supposed to reduce fitness by causing an overabundance of homozygous loci and increasing the probability of deleterious rare alleles that lead to inbreeding depression [37]. As inbreeding is related to homozygosity, the chances of offspring being affected by recessive or deleterious traits are therefore increased [38]. In fact, the assumption that a higher level of inbreeding or increased homozygosity correlates with cancer incidence has been proven already before on the genomic level [16].

Even the results of the $\mathrm{F}_{\mathrm{ROH}}$ support the higher inbreeding among cases compared with controls, although $\mathrm{F}_{\mathrm{ROH}}$ is discarding SNPs in regions outside of $\mathrm{ROHs}$ that are below our stringent length criterion. The fact, that we found no significant differences among cases and controls in the mean sum of shorter ROHs but highly significant differences for the longer ROHs supports the view that the differences in $\mathrm{ROH}$ length longer than $20 \mathrm{Mb}$ reflect effects of more recent consanguinity rather than LD pattern of ancient origin. It has been shown that consanguinity increased in Italy early in the 20th century and subsequently decreased. This has been explained by population growth in the early 20th century and changing demographics since then [39]. Another reason is the very large number of distantly related 
spouses in determining the population level of inbreeding [39]. With this source of a consanguineous population we had the unique opportunity to detect recessively inherited genomic regions for TC.

\section{Conclusion}

We showed evidence for long $\mathrm{ROHs}$ to increase the risk of TC. Higher inbreeding among cases supports the existence of recessive alleles affecting TC risk. The genetic architecture of TC is highly supported by a genetic model, in which the variants of a complex disease are more likely to be rare than common. They are also likely to be numerous with highly polygenic architecture and of a small individual effect at the population level. If this view of the genetic architecture of common complex diseases is correct, then it would be important to consider inbreeding as a factor having an influence on the disease.

Supplementary information is available at the journals website.

\section{Additional file}

Additional file 1: Figure S1. Example for recurrent $\mathrm{ROH}$ s in the telomeric region of chromosome 15 for 6 cases. (PDF $335 \mathrm{~kb}$ )

\section{Abbreviations \\ BP: base pair; CEU: Utah residents with ancestry from northern and western Europe; CHR: chromosome; Cl: confidence interval; F: inbreeding coefficient; FDR: false discovery rate; $F_{\text {st: }}$ Fixation index; GCTA: genome-wide complex trait analysis; GLM: generalized linear regression model; GRM: genetic relationship matrix; GWAS: Genome-wide association study; iHS: integrated haplotype score; kb: Kilo-base pair; LD: linkage disequilibrium; Mb: Mega base pair; MLM: mixed linear model; OR: odds ratio; PTC: papillary thyroid cancer; REML: restricted maximum likelihood; ROH: runs of homozygosity; SD: standard deviation; SE: standard error; SNP: single-nucleotide polymorphism; TC: thyroid cancer.}

\section{Competing interests}

The authors declare that they have no competing interests.

\section{Authors' contributions}

$H T, A F, F G, K H$, SL organized and designed the study. BC, GF, PH and SH performed the GWAS RE, CR, MC, AC and FB were responsible of the collection of samples. $\mathrm{HT}$ performed the statistical analysis. $\mathrm{HT}, \mathrm{AF}, \mathrm{KH}$ wrote and reviewed the manuscript. All authors read and approved the final manuscript.

\section{Acknowledgements}

The Italian part of the study has received financial support from the Istituto Toscano Tumori.

\section{Author details}

'Molecular Genetic Epidemiology, C050, German Cancer Research Center (DKFZ), Im Neuenheimer Feld 580, 69120 Heidelberg, Germany. ${ }^{2}$ Department of Biology, University of Pisa, Pisa, Italy. ${ }^{3}$ Department of Endocrinology and Metabolism, University of Pisa, Pisa, Italy. ${ }^{4}$ Blood Centre, Azienda Ospedaliero Universitaria A. Meyer, Firenze, Italy. ${ }^{5}$ Department of Genomics, Life and Brain Center, University of Bonn, Bonn, Germany. 'Division of Medical Genetics, University Hospital Basel, Basel, Switzerland. 'Department of Biomedicine, University Hospital Basel, Basel, Switzerland. ${ }^{8}$ Center for Primary Health Care Research, Clinical Research Center, Lund University, Malmö, Sweden.
Received: 11 September 2015 Accepted: 9 March 2016

Published online: 16 March 2016

\section{References}

1. Agate L, Lorusso L, Elisei R. New and old knowledge on differentiated thyroid cancer epidemiology and risk factors. J Endocrinol Investig. 2012;35(6 Suppl):3-9.

2. Li N, Du XL, Reitzel LR, Xu L, Sturgis EM. Impact of enhanced detection on the increase in thyroid cancer incidence in the United States: review of incidence trends by socioeconomic status within the surveillance, epidemiology, and end results registry, 1980-2008. Thyroid. 2013;23(1):103-10.

3. Tehranifar P, Wu HC, Shriver T, Cloud AJ, Terry MB. Validation of family cancer history data in high-risk families: the influence of cancer site, ethnicity, kinship degree, and multiple family reporters. Am J Epidemiol. 2015;181(3):204-12.

4. Cardis E, Kesminiene A, Ivanov V, Malakhova I, Shibata Y, Khrouch V, Drozdovitch V, Maceika E, Zvonova I, Vlassov O, et al. Risk of thyroid cancer after exposure to 1311 in childhood. J Natl Cancer Inst. 2005;97(10):724-32.

5. Hemminki K, Eng C, Chen B. Familial risks for nonmedullary thyroid cancer. J Clin Endocrinol Metab. 2005;90(10):5747-53.

6. Hemminki K, Sundquist J, Lorenzo Bermejo J. Familial risks for cancer as the basis for evidence-based clinical referral and counseling. Oncologist. 2008:13(3):239-47.

7. Bonora E, Tallini G, Romeo G. Genetic predisposition to familial nonmedullary thyroid cancer: An update of molecular findings and state-ofthe-art studies. Journal of oncology. 2010;2010:385206.

8. Gudmundsson J, Sulem P, Gudbjartsson DF, Jonasson JG, Masson G, He H, Jonasdottir A, Sigurdsson A, Stacey SN, Johannsdottir H, et al. Discovery of common variants associated with low TSH levels and thyroid cancer risk. Nat Genet. 2012;44(3):319-22

9. Gudmundsson J, Sulem P, Gudbjartsson DF, Jonasson JG, Sigurdsson A, Bergthorsson JT, He H, Blondal T, Geller F, Jakobsdottir M, et al. Common variants on 9 q22.33 and 14q13.3 predispose to thyroid cancer in European populations. Nat Genet. 2009:41(4):460-4.

10. Takahashi M, Saenko VA, Rogounovitch TI, Kawaguchi T, Drozd VM, TakigawaImamura H, Akulevich NM, Ratanajaraya C, Mitsutake N, Takamura N, et al. The FOXE1 locus is a major genetic determinant for radiation-related thyroid carcinoma in Chernobyl. Hum Mol Genet. 2010;19(12):2516-23.

11. Kohler A, Chen B, Gemignani F, Elisei R, Romei C, Figlioli G, Cipollini M, Cristaudo A, Bambi F, Hoffmann P, et al. Genome-wide association study on differentiated thyroid cancer. J Clin Endocrinol Metab. 2013;98(10):E1674-1681.

12. Bener A, El Ayoubi HR, Chouchane L, Ali Al, Al-Kubaisi A, Al-Sulaiti H, Teebi AS. Impact of consanguinity on cancer in a highly endogamous population. Asian Pac J Cancer Prev. 2009;10(1):35-40.

13. Kijas JW. Detecting regions of homozygosity to map the cause of recessively inherited disease. Methods Mol Biol. 2013;1019:331-45.

14. Spain SL, Cazier JB, Consortium C, Houlston R, Carvajal-Carmona L, Tomlinson I. Colorectal cancer risk is not associated with increased levels of homozygosity in a population from the United Kingdom. Cancer Res. 2009:69(18):7422-9.

15. Enciso-Mora V, Hosking FJ, Houlston RS. Risk of breast and prostate cancer is not associated with increased homozygosity in outbred populations. Eur J Hum Genet. 2010;18(8):909-14.

16. Wang $C, X u Z$, Jin G, Hu Z, Dai J, Ma H, Jiang Y, Hu L, Chu M, Cao S, et al. Genome-wide analysis of runs of homozygosity identifies new susceptibility regions of lung cancer in Han Chinese. Journal of biomedical research. 2013:27(3):208-14

17. Figlioli $G$, Kohler A, Chen B, Elisei R, Romei C, Cipollini M, Cristaudo A, Bambi F, Paolicchi E, Hoffmann P, et al. Novel genome-wide association studybased candidate loci for differentiated thyroid cancer risk. J Clin Endocrinol Metab. 2014:99(10):E2084-2092

18. Purcell S, Neale B, Todd-Brown K, Thomas L, Ferreira MA, Bender D, Maller J, Sklar P, de Bakker PI, Daly MJ, et al. PLINK: a tool set for whole-genome association and population-based linkage analyses. Am J Hum Genet. 2007; 81(3):559-75.

19. Anderson CA, Pettersson FH, Clarke GM, Cardon LR, Morris AP, Zondervan $K T$. Data quality control in genetic case-control association studies. Nat Protoc. 2010;5(9):1564-73.

20. Yang J, Benyamin B, McEvoy BP, Gordon S, Henders AK, Nyholt DR, Madden PA, Heath AC, Martin NG, Montgomery GW, et al. Common SNPs explain a large proportion of the heritability for human height. Nat Genet. 2010;42(7):565-9.

21. Dempster ER, Lerner IM. Heritability of threshold characters. Genetics. 1950;35(2):212-36 
22. Yang J, Lee SH, Goddard ME, Visscher PM. GCTA: a tool for genome-wide complex trait analysis. Am J Hum Genet. 2011;88(1):76-82.

23. Weller JI, Song JZ, Heyen DW, Lewin HA, Ron M. A new approach to the problem of multiple comparisons in the genetic dissection of complex traits. Genetics. 1998;150(4):1699-706.

24. Howrigan DP, Simonson MA, Keller MC. Detecting autozygosity through runs of homozygosity: a comparison of three autozygosity detection algorithms. BMC Genomics. 2011;12:460.

25. Team RC. R: A language and environment for statistical computing. 2013.

26. Lencz T, Lambert C, DeRosse P, Burdick KE, Morgan TV, Kane JM, Kucherlapati $\mathrm{R}$, Malhotra AK. Runs of homozygosity reveal highly penetrant recessive loci in schizophrenia. Proc Natl Acad Sci U S A. 2007;104(50):19942-7.

27. Pemberton TJ, Absher D, Feldman MW, Myers RM, Rosenberg NA, Li JZ. Genomic patterns of homozygosity in worldwide human populations. Am J Hum Genet. 2012;91(2):275-92.

28. Voight BF, Kudaravalli S, Wen X, Pritchard JK. A map of recent positive selection in the human genome. PLoS Biol. 2006;4(3):e72.

29. Fay JC, Wu Cl. Hitchhiking under positive Darwinian selection. Genetics. 2000;155(3):1405-13.

30. McQuillan R, Leutenegger AL, Abdel-Rahman R, Franklin CS, Pericic M, Barac-Lauc L, Smolej-Narancic N, Janicijevic B, Polasek O, Tenesa A, et al. Runs of homozygosity in European populations. Am J Hum Genet. 2008; 83(3):359-72.

31. Coop G, Pickrell JK, Novembre J, Kudaravalli S, Li J, Absher D, Myers RM, Cavalli-Sforza LL, Feldman MW, Pritchard JK. The role of geography in human adaptation. PLoS Genet. 2009:5(6):e1000500.

32. Oleksyk TK, Smith MW, O'Brien SJ. Genome-wide scans for footprints of natural selection. Philos Trans R Soc Lond Ser B Biol Sci. 2010;365(1537):185-205.

33. Siraj AK, Khalak HG, Sultana M, Al-Rasheed M, Bavi P, Al-Sanea N, Al-Dayel F, Uddin S, Alkuraya FS, Al-Kuraya KS. Colorectal cancer risk is not associated with increased levels of homozygosity in Saudi Arabia. Genet Med. 2012; 14(8):720-28.

34. Woods CG, Cox J, Springell K, Hampshire DJ, Mohamed MD, McKibbin M, Stern R, Raymond FL, Sandford R, Malik Sharif S, et al. Quantification of homozygosity in consanguineous individuals with autosomal recessive disease. Am J Hum Genet. 2006;78(5):889-96.

35. Li LH, Ho SF, Chen CH, Wei CY, Wong WC, Li LY, Hung Sl, Chung WH, Pan $\mathrm{WH}$, Lee MT, et al. Long contiguous stretches of homozygosity in the human genome. Hum Mutat. 2006;27(11):1115-21.

36. Gibson J, Morton NE, Collins A. Extended tracts of homozygosity in outbred human populations. Hum Mol Genet. 2006;15(5):789-95.

37. Spielman D, Brook BW, Briscoe DA, Frankham R. Does inbreeding and loss of genetic diversity decrease disease resistance? Conserv Genet. 2004;5(4):439-48.

38. Nabulsi MM, Tamim H, Sabbagh M, Obeid MY, Yunis KA, Bitar FF. Parental consanguinity and congenital heart malformations in a developing country. Am J Med Genet A. 2003;116A(4):342-7.

39. Cavalli-Sforza LL, Moroni A, Zei G. Consanguinity, inbreeding, and genetic drift in Italy (MPB-39). Princeton: University Press; 2013.

\section{Submit your next manuscript to BioMed Central and we will help you at every step:}

- We accept pre-submission inquiries

- Our selector tool helps you to find the most relevant journal

- We provide round the clock customer support

- Convenient online submission

- Thorough peer review

- Inclusion in PubMed and all major indexing services

- Maximum visibility for your research

Submit your manuscript at www.biomedcentral.com/submit
Biomed Central 